Aesthetics in

Dermatology and

Surgery

\title{
Editorial
}

We are extremely pleased to release the first issue of Aesthetics in Dermatology and Surgery - Journal of the 5-Continent Congress (5CC).

Why do we need another journal in this field? Simply because Aesthetics in Dermatology and Surgery follows a new concept with peer reviewed and non-peer reviewed types of papers which sets it apart from its competitors on the market and meets the specific needs of the 5CC and its attendees. In other words, it's not "just another journal" out there.

\section{Scientific Core}

At its heart, the journal will have a core of high-quality articles undergoing thorough peer review. Article types comprise:

- Best Practice: Presenting surgical or medical treatments and a comparison of their advantage compared to current approaches. Video files accompanying this type of paper are more than welcome.

- Reviews: Comprehensive papers on a timely topic.

- Short \& Original: Original research with descriptions of significant, original experiments in basic science or translational research. Papers should be based on novelty and scientific soundness. The submission of raw data as supplementary material is strongly encouraged.

\section{Easy-to-Read Supplementary Articles}

Papers are collected, edited, and approved under the auspices of section editors. Article types comprise:

- Knowledge Transfer: Abstracts of papers selected from related Karger journals in dermatology and surgery and commentaries as to why these papers from clinical research are of importance to the aesthetic dermatologist and surgeon and what can be learnt from them, thus allowing for translation from research to clinical practice.

- What's New: Innovations from industry and clinical practice are featured with a clear connection to the sciences.

- Interviews: Experts provide advice on different aspects on aesthetics in daily practice.

\section{Bringing Together the Right People}

This journal represents the collaborative efforts of (1) an international Editorial Board of highly regarded clinicians; (2) Karger Publishers and its 126 years of experience of publishing cutting-edge science; (3) the 5CC.

However, we can only lay the foundations for a stronger global community in aesthetics. For this journal to reach its potential, we need your support. So, come and be a part of it. Please submit articles, ideas for articles, or highlight new developments. Aesthetics in Dermatology and Surgery is a service for you - we invite you to help us shape it.

Bradley Bloom, New York, USA, Editor-in-Chief Christine Dierickx, Boom, Belgium, Advisory Board Michael Gillner, Bassum, Germany, Advisory Board Michael H. Gold, Nashville, USA, Advisory Board David J. Goldberg, New York, USA, Advisory Board Henry H.L. Chan, Hong Kong, SAR, China, Section Editor Klaus Fritz, Landau, Germany, Section Editor Maurice Adatto, Geneva, Switzerland, Section Editor Moshe Lapidoth, Petach Tikva, Israel, Section Editor 